\title{
Perceptions of the Drivers of Sexual and Gender Based Violence in Post Conflict Northern Uganda
}

\author{
Paul Bukuluki ${ }^{1, *}$, John David Kisuule ${ }^{2, \star *}$, Alex Bagabo Makerere ${ }^{1, \star * *}$, \\ Berit Schei ${ }^{2, * * * *}$, Johanne Sundby ${ }^{2, * * * * *}$ \\ ${ }^{1}$ School of Social Sciences, Makerere University, Kampala, Uganda \\ *Tel: +256-772-462100, ***Tel: +256-785 673967 \\ 2Department for General Practice and Community Medicine, Institute of Health and Society, \\ The Medical Faculty, University of Oslo, Oslo, Norway \\ ${ }^{* *}$ Tel: $+4722850514,{ }^{* * * *}$ Tel: $+4722850550,{ }^{* * * * *}$ Tel: +4722850550 \\ * -*****Email address: pbukuluki@gmail.com ,j.d.k.alao@medisin.uio.no , \\ alexbagabo20@gmail.com , berit.schei@ntnu.no,johanne.sundby@medisin.uio.no
}

\begin{abstract}
This paper explores the perceived forms and drivers of sexual and gender based violence in post conflict settings with focus on Northern Uganda. It applied qualitative approaches primarily using indepth interviews, focus group discussions and key informant interviews. Study findings revealed that although all forms of violence are perceived to be prevalent, physical and emotional violence were perceived to be the most occurring. Men were perceived to be the main perpetrators of violence. However, there were cases of men who reported to experience violence from women. Few men reported violence to authorities because it was perceived to be stigmatizing; such men would be perceived as weak in a patriarchal society that perceives ideal men to be strong and less susceptible to physical, emotional and sexual abuse. Early marriages are a major form of gender based violence which was perceived as normal in a number of communities despite the evidence that it contributes to negative social and reproductive health outcomes. Sexual violence cases in form of rape, defilement as well as incest were perceived to be on the rise in the sub-region. The study identified several drivers of SGBV including poverty, power imbalances in access to and control over resources, insecurity, blaming HIV infection on female partners, HIV related stigma and discrimination, alcohol and substance abuse.
\end{abstract}

Keywords: Sexual; Gender; Violence; Drivers; Post conflict; Northern Uganda

\section{INTRODUCTION}

This paper is based on a pilot study exploring the effectiveness of work done by actors in civil society on Sexual and Gender Based Violence (SGBV) in the post conflict settings of Northern Uganda. The overall objective was to explore the effects of interventions implemented by CSO in addressing GBV in northern Uganda, and to make recommendations with action areas to contribute in improving the effectiveness of SGBV policy and programming in post conflict situations. The study was conducted between September 2011 and December 2012 in the districts of Gulu, Kitgum, Amuru and Nwoya. The study was conducted under a collaborative arrangement between Makerere University School of Social Sciences and the 
Institute of Health and Society at the University of Oslo. Other partners were Care International in Uganda and Norwegian Refugee Council. The study was funded by NORAD. One of the main interests of the study was to explore the forms and drivers of SGBV in post conflict settings. Therefore, this paper is devoted to discussion of the perceived forms and drivers of SGBV in post conflict northern Uganda.

\section{BACKGROUND}

Sexual and gender based violence (SGBV) is a pervasive human rights, public health, and a development problem (Sundby et al., 2013). Sexual and gender based violence is broadly conceptualized to comprise all forms of physical, psychological and sexual violence that are related to the survivor's gender or gender role in a society or culture.(IGWG of USAID, 2006, Keesbury and Askew, 2010). SGBV in stable and conflict settings is perceived to have a feminine dimension because the burden tends to fall heavily on women and girls. However, this does not mean that men and boys do not face the brunt of SGBV in these contexts. What is quite clear is that the women have been more responsive in reporting cases of violence especially in the formal archives of Police and the formal justice systems. Low reporting of violence against men could be attributed to the cultural construction of masculinity that makes it relatively stigmatizing for men to report violence to formal structures in the community and local governments. The femininisation of SGBV is quite comprehensively captured in the literature. For example, available estimates indicate that one out of three women will be beaten, coerced into sex, or otherwise abused in her lifetime, with rates of abuse reaching $70 \%$ in some countries (Heise, Ellsberg \& Gottemoeller, 1999). SGBV is not limited to developing countries. Neither is it limited to conflict and post conflict settings. However, because of the disruption of social order and social control systems, conflict and post conflict settings are perceived to create conditions that exacerbate SGBV. Quite a number of studies indicate that women vulnerability to sexual violence particularly increases in emergency settings or in contexts of displacement (IASC, 2005; Skjelsbæk, 2006). The concerns about SGBV are justified by its profound impacts on the social relationships, social identity, mental health, reproductive health, physical, psychosocial and economic welfare of women, as well as on child health (Kishor and Johnson, 2004). Many women may live in isolation and loneliness because they do not dare to return to their families and/or communities due to the shame they feel and lost social identity, resulting from SGBV (Skjelsbæk, 2006). The social and political significance of SGBV against women especially in the context of war can be traced right from the Middle Ages to the first and second World Wars (ibid). For example, Inger Skjelsbæk noted that:

Sexual violence in war is as old as war itself. History has shown us that the female body is an extension of the battlefield, where victories and defeats can be manifest in different modes of sexual gratification by the male soldier... The power of rape, however, is more unanswered, in that war creates opportunities for rape to be carried out with impunity for the majority of its perpetrators. The power of the perpetrators lies not only in the fact that the likelihood of conviction for these crimes is lower in 
times of war than in times of peace, but also in the fact that the perpetrators victims tend to remain silent about the ordeals they have suffered ${ }^{1}$ (Skjelsbæk, 2006, 3).

In developing her arguments about rape as a weapon of war, Inger goes ahead to cite Brownmiller (1991) who in her seminal work on Men, Women and Rape, argued that "rape has accompanied wars of religion and revolution, and it has been a weapon of terror and revenge, as well as a way to relieve boredom" (Brownmiller 1991, 31; see Skjelsbæk, 2006, $3)$. It has been argued that the political significance of rape in war came into the limelight particularly during the war in Bosnia and Herzegovina (from 1992 to 1995). Sounding rather sarcastic, Inger Skjelsbæk made an observation that during this war:

It became clear from the early months of the war that rape against women of opposing ethnic groups constituted an integral part of the war strategy. What made the Bosnian situation unique from previous wars was the fact that the rapes made headlines in the national and international press even as they were taking place. It became clear that rape was used as a tool in a systematic political campaign of ethnic cleansing and could no longer simply be regarded as "collateral damage" or something that happens in the heat of battle. Rape and sexual violence took on a political significance of their own, and had to be dealt with on a political level both domestically and internationally (Skjelsbæk, 2006, 4).

Two important steps were taken during and after this war that increased political significance and international recognition of rape and sexual violence. 1. Establishment of the International Criminal Tribunal for the former Yugoslavia (ICTY) in The Hague in the Netherlands in 1993; and 2. Making a SGBV became a key item on the agenda of the 2006 International Conference in the Great Lakes Region (GLR) on the Protocol on the Prevention and Suppression of Sexual Violence against Women and Children. This conference observed that SGBV inhibits the ability of women to contribute to, and benefit from, development and to enjoy their rights and fundamental freedoms, in private or public life. This is contrary to the relevant international instruments such as the Charter of the United Nations 1945, Security Council Resolution 1325, the Universal Declaration of Human Rights 1948, the African Charter on Human and Peoples' Rights 1981.

\section{MAGNITUDE OF SGBV IN UGANDA}

Sexual Gender Based Violence (SGBV) is a widespread problem in Uganda. Data based on the 2006, Uganda Demographic and Health Survey (UDHS) shows that $39 \%$ of women and girls aged 15-49, had ever experienced sexual violence, compared to $11 \%$ for men, and $59.6 \%$ of women have experienced physical violence, compared to $53 \%$ of men. The majority of gender-based violence against women in Uganda is committed by an intimate partner. For example, according to the UDHS (2006), more two-third women (68\%) who have been in marital relationships had experienced one kind of gender based violence, more commonly by

\footnotetext{
${ }^{1}$ What she forgets to consider though is that in recent past young men and boys have become victims of sexual abuse during violent conflict and when in custody during post conflict situations.
} 
an intimate partner. Five in 10 women had experienced physical violence from their current husband or intimate partners while $8 \%$ of these experienced the violence from their former husband or intimate partner; $36 \%$ had experienced sexual violence (UBOS \& Macro International, 2007). Similarly, a study carried out by the International Centre for Research on Women (ICRW) in 2009, revealed that more than $80 \%$ of women consulted have experienced physical, sexual or psychological violence at some point in their marriage or intimate relationship (ICRW, 2009).

It has also been aptly documented that 24 percent; that is more or less one in four women aged 15 to 49 reported that their first sexual intercourse was forced against their will, and more than half of these (54 percent) first suffered sexual violence below the age of 18 . The 2011 National Report on Sexual and Gender-Based Violence also indicates that between one-third and two-thirds of known sexual assault victims are of age 15 or younger (MoGLSD, 2011).

Girl children have also been documented to be prone to abuse through socially constructed harmful norms and practices that are tolerated in some communities. A number of harmful traditional practices targeting children, such as female genital mutilation/cutting (FGM/C), forced and early marriages for girls have also been reported. Some studies have shown that while age at first marriage is generally increasing, in many parts of South Asia and sub-Saharan Africa, a substantial proportion of girls are still married before their $18^{\text {th }}$ birthday (Lloyd, 2005). It has also been documented that if current marriage patterns do not profoundly change, over 100 million girls are likely to be married during their adolescence in the next decade (Bruce, 2005). A number of scholars have observed that the early marriage impacts significantly on the quality of a girl, changing her focus from education and personal development, to family life and motherhood (Mensch, Bruce, Greene, 1998).

Similarly, the UDHS (2006) indicated that over 20 percent of adolescent girls were married before 18 years, compared to only 2.4 percent of boys. In addition, 57 percent of the women aged 20-25 were already married before the age of 18. Due to the high prevalence of child brides, child mothers are also pervasive in Uganda. For example, at least 43 percent of women aged 20-25 had given birth before the age of 18 (UBOS, 2006). There are also indications gender based violence is tolerated and is leaning towards normalization. The normalization of violence is partly reflected in the internalization by women of social norms that tolerate abuse against women and girl children. For example, according to the UBOS and ICF Macro (2012), about "six in ten women (58 \%) believed that neglecting a child, denying a husband sex, burning food, disobeying their husbands or being unfaithful would justify a husband's violence (UBOS and ICF Macro, 2012).

\section{VIOLENCE AGAINST WOMEN IN CONFLICT-AFFECTED AREAS}

Twenty-two years of a protracted and intractable violent conflict between the Lord's Resistance Army (LRA) and the Government of Uganda (GoU) left their mark on the Acholi people of Northern Uganda (Finnstrom, 2008). According to the Liu Institute for Global Issues (LIGI) and the Gulu District NGO Forum (GDNGOF) $(2007,2)$, 'the consequences of disorder and violence have fallen disproportionately upon the women and children of Acholi-land (also see Isis-WICCE, 2006)

Women and children in war affected districts in Northern Uganda have borne the brunt of violence in several ways. During the armed conflict, thousands of women were exposed to rape or forced into sex by both LRA and government forces. It has been documented that the LRA engaged SGBV acts such as willful killing, rape, mutilation, torture, massacres, 
intimidation, beatings, large-scale abductions, forced recruitment of adults and children, sexual violence against girls whom it assigns as "wives" or sex slaves to commanders, and large-scale looting and destruction of civilian property (Branch 2004). For example during the heights of displacement, a study by UNICEF (2005) showed that, an estimated 60 percent of women in the largest camp for internally displaced persons (IDPs) in war-torn northern Uganda [had] encountered some form of sexual and domestic violence.

In addition, due to the social and economic insecurity brought on by the war, many internally displaced girls and women were exposed to multifarious forms of sexual and genderbased violence, whether in physically forceful ways such as rape or forced sex by intimate partners and camp dwellers, or in structurally forceful ways such as transactional sex for subsistence (IASC 2005, Isis-WICCE, 2001, JRP, 2012). In a another study undertaken in Northern Uganda in 2004, a woman living in one of the many IDP camps in the region told investigators "rape is rampant here...A woman was recently harassed by two men who held her legs wide open to observe her private parts and allowed another man to rape her while they observed" (UNICEF et al., 2004). The breakdown of moral and social order and social control mechanisms, poverty and poor access to resources, occasioned by the over two-decade violent conflict, left many women and girls vulnerable to physical abuse and exploitation, rape and human trafficking.

The GBV Information Management System(GBV IMS) revealed that between January 2009 and March 2010, an average of 227 GBV cases were reported every month to 5 NGOs providing GBV response services in the districts of Gulu, Amuru, Pader, Kitgum and Dokolo. Majority (70\%) of these cases (161) were cases of sexual assault and defilement of children. It is further noted that sexual violence $(40 \%)$ constituted the highest number of reported cases per month followed by physical violence $31 \%$. Of the cases of sexual violence, $90 \%$ of the victims were girls below 18 years (UNICEF, 2012). Unfortunately, violence remains normalized and socially condoned. For example, the 2011 UDHS found that a high percentage of women aged 15-49 years in the Northern region harbor accepting attitudes towards physical violence. About four in ten women $(42.1 \%)$ believed that "a husband is justified in hitting or beating his wife for specific reasons, including neglecting a child, denying a husband sex, burning food, disobeying their husbands or being unfaithful would justify a husband's violence (UBOS and ICF Macro, 2012).

\section{NEGATIVE PEACE VS. POSITIVE PEACE}

It is important to note that while relative negative peace and stability has returned in Northern Uganda, the effects of the two decade violent conflict still linger. The region is yet to experience positive peace because although the guns have largely fallen silent, the structural and underlying causes of the violent conflict still remain prevalent ${ }^{2}$ (Galtung, 2001) in most parts of the region. The region is among those that are experiencing the highest brunt of absolute poverty in Uganda. Reparations for victims/survivors of different forms of atrocities committed during the war are yet to be effectively done. This has not been helped by the fact that although a Peace, Recovery and Development Programme (PRDP) was launched, its implementation has for long suffered from pervasive forms of corruption and mismanagement (Auditor General's Report 2013).

\footnotetext{
${ }^{2}$ Negative Peace is an incomplete form of peace, but still a peace without physical violence; whereas Positive Peace should be striven for as the fulfillment of an ideal. Positive Peace he (Galtung) conceptualized as mirror image of Structural Violence. It should be understood as a state without structural violence
} 
Given the above magnitude of SGBV in the Acholi sub-region, it was significant to establish the forms and structural, socio-economic and psychological drivers of SGBV in the region.

\section{METHODS}

\section{1. Research Design}

An exploratory and descriptive design was applied because the study had an interest in exploring and providing an in-depth description of the forms and drivers of SGBV. The study employed a predominantly qualitative approach in data collection, analysis and presentation of findings. We leaned towards the conceptualization of qualitative research by Kirk and Miller who define qualitative research as an approach that involves watching people in their own territory and interacting with them in their own language, on their own terms (Kirk and Miller, 1986). These authors also noted that in qualitative research, the researcher is able to understand behaviour or human actions from the informant's own frame of reference (Kirk and Miller, 1986).

Study area: This study focused on four districts in northern Uganda, namely: Gulu, Amuru, Kitgum, and Nwoya.

\section{2. Data collection}

We utilised essentially qualitative methods of data collection, namely;

Key Informant Interviews (KIIs): Sixty (60) key informant interviews were conducted with selected informants from organizations and institutions involved in GBV preventions and response in the four districts. Individuals who were associated with specific programs were asked to provide information on their programs and, in particular, the results of any operation research carried out. Interview guides were used in conducting the KIIs. This approach allowed for a deeper engagement of the study participants to generate learning and understanding of the contextual of the forms and drivers of SGBV in post conflict situations.

Desk study: The desk Study involved a review of several documents related SGBV, including any baseline studies, operational researches, monitoring and evaluation reports, legal and policy documents, and records of Police and the judiciary. A document checklist was generated and later a thematic issues checklist was generated to guide abstraction of information and data from the various documents.

In-depth Interviews (IDIs): Sixty (60) IDIs were conducted survivors of SGBV and 30 IDIs were conducted with perpetuators of SGBV. An in-depth interview guide was used to explore their experiences and views with respect to SGBV.

Focus Group Discussions (FGDs): Eight (8) focus group discussions were conducted with cultural leaders. FGD guides were used to elicit collective views about GBV as well as generate information that could be difficult to elicit at individual level.

\section{3. Data Analysis}

Several activities were undertaken in the course of analysing and processing data for this study. Firstly, data recorded during IDIs, FGDs and KIIs was transcribed, simultaneously translated from the local language to English and edited for use in the reporting. This process was done on a daily basis for every interview/discussion conducted. A microanalysis of 
transcripts was done to summarise data and generate key themes in line with the study objectives. Data analysis was done manually and some verbatim extractions were made from the transcripts that were later inserted directly into the report. An interpretative and explanatory approach was used to do content analysis and draw conclusions from the data guided by the study objectives and emerging themes from the study findings. This analysis was used to analyse the meaning of SGBV, forms and drivers of SGBV in the post conflict settings.

\section{4. Ethical considerations}

Research approval was sought from the Uganda National Council for Science and Technology. Verbal consent was sought from all participants and they were informed of the objectives of the study. Participants were informed that this is a voluntary exercise and were free to decline participation in the study or answering certain questions without any adverse consequences. The confidentiality of all the information gathered was strictly protected. Records such as tape recorders and notebooks were treated with strict confidentiality.

\section{FINDINGS}

\section{1. Perceived Forms of SGBV in Post conflict northern Uganda}

This study revealed several forms of SGBV including fighting, quarrelling, and divorce, defilement, rape, early marriages and widow inheritance. These have been categorized under; physical violence, emotional (psychological) violence, sexual violence and socio-economic violence.

\section{2. Physical Violence}

This often involves physical assault i.e. beating, punching, kicking, biting, and burning of a person. It is often used in combination with other forms of sexual and gender-based violence. This form of violence is mostly perpetuated by a spouse, intimate partner, or family member (UNHCR, 2003). The study revealed that the most common form of physical violence is beating of a partner mostly perpetuated by men. As noted from the participants' expressions below, the causes for this form of violence included; lack of communication and respect among couples, drinking too much alcohol, neglecting family responsibilities, sexual denial and polygamy among others.

Physical violence is mostly prevalent during harvest time when people are free from garden work and the men go on a drinking spree. Also during harvest when men go to sell the crops, they intend to spend all the money on alcohol and come back home without any thing. When their wives ask them about the money, they start fighting (KII, $\mathrm{CSO})$

My husband beat me when I refused to show him where I kept the food to use in the future. I knew he wanted to go and sell and go for drinking but I refused and he started to beat and abuse me... (43yrs Female survivor, Gulu district)

...sometimes you find that the man will live his first wife at home to another home with children without even giving any money for food, so because of this, the first woman will tend to follow the husband up to where he has gone, so from there the two or three of them will spark in to a serious conflict (Local leader, Kitgum District) 
"...A man may come back home drank and smelling and the wife refuses to have sex with him. But also alcohol especially the new gin makes men important or not to function well sexually and this makes their wives angry, aggressive or get other lovers (Religious leader, Kitgum).

In addition, the study also noted there were some cases of violence against men. Male GBV survivors claimed that often they were beaten when they were drunk. They expressed that their situation was known to some people especially neighbors in the areas where they lived something which disturbed them a lot and caused them shame, and social isolation because people both men and women were laughing at them. None of them had officially sought for help either from the local authorities or NGOs but all of them had tried to solve their problems through family members and close friends but this did not helped them. They felt that this was a family matter and also that the authorities and NGOs had no any appropriate solutions for them.

...My wife is twenty eight years old and we have been married since she was 16 yrs old and we have 4 children. The eldest is 11 yrs old. When I used to work as a driver in Sudan everything was ok. But about five years ago I left that job and I am now a peasant here at home. After gardening I like sitting with friends and we drink together. But she only wants me to be at home. She is very strong and each time I come back home she beats me properly in front of my children. Sometimes my big daughter asks her to stop beating me but she doesn't stop. At times when she is beating me the children start crying. We have held many meetings with her relatives and mine but she has never changed. Recently we had a meeting with her uncle who is the Local Council 3 (LC3) chairman of this area and he warned her to stop it. When I want sex she often refuses but when she wants it and I try to refuse she harasses and insults me. Because of this I got another woman somewhere in another village but since she doesn't know about this affair I cannot sleep at her place. I am giving her time but one day I am planning to pretend that I am drank and when she will try to beat me although she is strong I will teach her a lesson... (Male Survivor 39 yrs old, Kitgum).

...She waits when I am drunk and then beat me. Sometimes I try to fight back but because that time I am drunk and weak she over powers me. Everybody here knows about it. Even the pupils from my school who live near us know it. I feel so bad because they have informed other pupils in school and my respect is very low. She goes out when she wants and comes when she wants. Women who know that she beats me admire her because she has a lot of freedom and I cannot manage to control her. One time my young brother threatened to come and beat her if she doesn't stop misbehaving. I tried to chase her away from my home but she refused. I am a strong man and I can beat her but we have many children and this will not be good. Our eldest son is 23 years old. But life cannot continue like this I think of what to do next (Male survivor 54 years, Kitgum).

\section{3. Sexual Violence}

Sexual violence is a result of several complex and interacting determinants which include cultural practices, gender inequality, societal breakdown, violent masculinities, and competition over resources (Sigsworth, 2008). This study revealed that the most common forms of sexual violence include rape, defilement, sexual harassment, incest and early marriages. Rape and 
defilement was reported to occur when there are auctions in the community and during festive seasons. It was noted mostly women are the victims of this from violence. It was noted that sexual exploitation of young boys by older women also prevails within the post conflict context.

Defilement is very common for both boys and girls although the number for girls including maids is higher. There are many cases involving men sleeping with their step daughters when there is a conflict in the marriage (Judicial officer, Gulu district)

... There are many young boys who acknowledge their preference to have sex with old women who have money to look after them nicely instead of committing defilement with young girls and be imprisoned. But there are reported cases where old women or prostitutes keep young boys under age in their residences for one week or even longer defiling them without the parents or relatives knowing where these boys are (local leader, lujojo village Kitgum District) ...rape is also another form of violence in our community; women and young girls are forcefully slept with like what they did to my daughter (Mother of an 8 year old female in Nwoya district)

... a man who is the head of the family that I went to grind (millet) started following me stopped me but I refused and continued walking. He told me to wait because he want to send me to my sister's husband then I stopped and instead he pull me into one unfinished building and tie my mouth then forced me into a sex and after finishing he ran away ( 22 year old female survivor, Kitgum)

Early marriages were also cited to be common. Young girls in marriages usually lack status and power within their marriages and their households. This exposes them to domestic violence, sexual abuse, and isolation from their families and communities. Study participants revealed that parents of young girls have forced their girls as young as 15 years into marriages for material gains. Reflecting on this issue, one of the field officers noted that;

...when a girl is 15years old, they will say that the she is now ready for marriage, and there other parents who also tent to negotiate for the girls marriage, and at some point when defilement occur there other parents who tent to negotiate from home so that they get money out of their daughter (Field officer CSO, Nwoya)

\section{4. Socio-economic violence}

This form of violence includes acts of discrimination, denial of economic opportunities or services, social exclusion based on sexual orientation among others. This study established that the most common form of socio-economic violence is denial of women the right to property ownership and inheritance and their right to work. It was noted that in northern Uganda, property ownership is virtually Patrilineal. Therefore upon the death of a husband, his family disinherits the widow in the guise of ensuring that the property devolves to a male adult who is a relative of the deceased. Often women are evicted from their land, homes and stripped off of their possessions as expressed in the remarks below;

The other common form is land conflicts which affects mostly widows and children. This is one of the unfair forms of the culture that states that if a man dies, the brother takes over the property. The brothers usually drive away the wife and children of the deceased and inherit everything... (KII CSO, Gulu District) 
...There are issues grabbing widows' property when their husbands have died and different forms of physical violence. They also have economic violence which is very difficult to see but we have also noted that it is there. The DHS has shown that it is there. (KII Official, MoGLSD)

It was also revealed that some men deny their wives to work or get involved in income generating activities. There were various reasons for this. But some of them cited by key informants were:

a) These women spend all the money earned on themselves or their parents etc without buying anything in the home.

b) When a woman has gone to work there is nobody at home to care for the children.

c) Women working in offices intend to put their money before their husbands. Thus because they are earning money, the respect for their husbands becomes less. This is very common when a woman earns more than her husband or when he loses his job. But at times men try to stop their wives from working because culturally a man is supposed to provide for the wife.

Local authorities reported that they register many divorce and physical violence cases due to economic reasons. Some men have gone to the extent of confiscating, burning or destroying their wives' academic papers so that they are not able to get jobs.

\section{5. Emotional (Psychological) Violence}

Emotional abuse is often referred to as a covert form of domestic violence where victims receive verbal abuse. It is a form of abuse characterized by a person subjecting or exposing another to behaviour that may result into psychological trauma, including anxiety and chronic depression (UNHCR, 2003). There is limited information related to emotional violence against women in homes and at community level. However, emotional violence is more common than any other forms of violence in families. Women, girls and men all reported that they are 'battered' psychologically by their partners and family members.

Emotional violence is very common. Most men quarrel with their wives each time they get drank but even when they are not drunk. They start quarreling even before they reach home. By the time he enters the house, the wife is afraid of him or has disappeared and hidden herself. But there are many men who are also in a similar situation. The worst bit is that men hardly talk about it and many of them are depressed resorting too much drinking. Therefore some men are drinking to too much because of SGBV in their homes. Others have decided to have extra marital love affairs (Local leaders, Amuru, Gulu and Kitgum).

My husband quarrels with me every day in front of the kids. I just keep quiet and not answer him. Sometimes I prefer that we should fight physically and finish with the matter instead of him humiliating me in front of the kids (40 year old Female survivor, Nowya).

We have been married for 25 years. In the past we used to physically fight a lot. But when the children grew up and some joined boarding schools he stopped beating me. But when he is drunk he insults by calling me all kinds of names. Even when I leave and 
go to bed, he stills insults me from the sitting room. He becomes worse when he wants sex and I refuse. I have shared my experiences with some friends and my brothers. But they said that since he doesn't beat me I better stay and with time he will stop that too (50 year old female survivor, Kitgum).

I don't insult her but she does so. At home I do help her with all house work etc. When I come back in the evening she says that I am dirty and smelling so I should not move near her. When we have domestic problems she discusses them with the neighbours and visitors. When we have visitors and I say something, she tells them that I am lying. Both of us have been Catholics but two years ago she become a Pentecostal and now she wants us to get wedded in her church but I do not want because I am not interested in joining her church. Also in her church people are not allowed to drink beer. Nowadays the wedding issue makes her to insult me that I am not a believer, I am a liar etc. All these things make me mad at her. (50 year old male survivor, Kitgum)

However, emotional/psychological violence sometimes results from other forms of violence. For example, some of the survivors who had been sexually or physically assaulted reported perpetuating emotional violence on others as a result of the previous experiences of violence.

\section{6. Perceptions of drivers of SGBV in Post conflict Northern Uganda}

The study revealed that there are a number of structural, social and psychological drivers of SGBV and these include among others, poverty, access to and control over property, women empowerment, insecurity, HIV and AIDS, alcohol and drug abuse, weak legal justice system, and cultural norms and values.

Poverty and access to and control of productive resources: Economic inequalities are one of the major drivers of SGBV at all levels; that is, individual, household and community levels. These inequalities are evident in the utilization of household resources and in access to and control over property, household income and others. Such inequalities contribute to women's subordinate position by ensuring they remain dependent on their husbands, thus reducing their capacity to partake in decision making within the home and the community.

Some of the examples given by survivors of SGBV who have been victims of domestic violence resulting from control of resources in the home depict a situation where women's rights have been infringed upon with men taking over control and allocation of productive resources.

I think it was common because of poverty among people in the sense that in a household, the husband or wife may not be able to pay school fees, meet household needs, among other things. With that, conflicts can start between the two on who to provide school fees and when a solution is not got conflicts arise and thus GBV. (Female survivor, 25yrs)

... a man decides to steal the food stuff in the home and go and sells it. So when the wife realizes that the food was sold and tries to find out from the man, the answer she receives are beatings from the husband and, serious beatings (Survivor 8yrs, Nwoya)

Yes if I want to sell food stuff or anything in the home, I can inform my wife but I do not need to ask for permission from her. If you ask for permission from a woman, you will 
never sell anything in the home because she will always say no or demand that you must show her the money you got (Male Informant 32 yrs, Gulu).

Insecurity: This study established that insecurity during the conflict was a major driver of SGBV. Due to the prolonged conflict in northern Uganda families became prone to conflict violence such as abductions, forced marriages, rape defilement and incest, mostly committed against women and girls during the conflict (also see JRP, 2012). Findings of this study revealed that the perpetrators tend take advantage of the conflict to commit acts of SGBV knowing that the risk of identification is low. Remarks from several study participants below reveal that women were gang raped and abducted, and congestion in the camps exposed risks of violence with in homes and the community

Sexual and domestic violence was common because of the congestion in the camp and thus people used to conflict amongst them in homes and in the community. (Female survivor, 28yrs)

...they used to tell us not to walk at night because you can meet the rebels and they rape or kill you. It happened to me when I was trying to move to another village but it was during the day and I met them with two other women and they raped all of us and then told us to run or we will be dead. I was too weak to run but I tried... (Female survivor, Gulu)

$L R A$ raped many women and some of them were taken and never came back. We don't even know what happened to them, maybe they became wives. Some who came back had children and they told us they were everyone's wife, any man in the jungle could be their husband and the women had no choice... (Female survivor, Nwoya)

Deconstruction of the traditional roles of men and women: Extended periods of encampment in IDP camps compounded SGBV. The loss of the traditional family settings which allowed for controls within the rural setting was disintegrated as a result of the war. Men were deprived of their livelihoods and could not go to work because of insecurity. Most provisions were provided by relief agencies, the organization took over the traditional and primary role of men as that of provider, and this took away some powers men wield that are linked to this masculine roles and socialization.. In such settings, men were increasingly idle and their frustrations of being unable to live up to the masculine ideals of being the provider would predispose them to violence against their partners/wives, (also see Okot, Amony and Otim, 2005; Bukuluki and Mugisha, 2010). Interviews with KIIs revealed this as deconstruction of gender roles;

Now in the post conflict setting which we are in right now, you see people have lived in camps for over two decades and that period tends to deconstruct the traditional roles of women and men, deconstruct those notions or patriarchy and so forth. That power is now lost. They are not in charge and some studies have suggested that the men react to the feeling of lost power, masculinity through violence. (Senior officer, MGLSD)

...Today because of the war, an Acholi man is like a wounded elephant or an elephant which has been attacked by many lions at ago. It loses energy to walk or fight the lions which over power it and kill it. So the war made an Acholi man to loose his power, respect and energy to fight against the white man's behaviors that our women and children learned in the camps (KII CSO, Gulu). 
Similarly, gender inequalities and norms were recurrent themes which came up throughout discussions with a cross section of participants on the drivers of SGBV. The study also revealed that gender-related norms that support male superiority and entitlement, female subordination, tolerate or justify violence against women, contribute to SGBV in northern Uganda.

One of the main causes of violence is the conflicting culture and misunderstanding of women's rights. For example in our culture a woman is supposed to carry water for the husband, but some women who don't understand these rights will say, after all we have rights so you find that the man will get annoyed and this will result into a serious problem or fights. It is therefore, our work to make them understand their rights (Male survivor, Gulu).

HIV and AIDS - Disclosure, Discordance, Stigma and Discrimination: HIV and AIDS pandemic has created an enabling environment for SGBV especially where issues of disclosure and discordance are concerned. Violence has been evidenced in cases where one partner tests positive for HIV while the other is negative and this has created unprecedented cases of physical and emotional abuse. Violence in the case of HIV/AIDS is not only meted out by a partner but also the extended family and the community at large. Respondents revealed that they have undergone psychological and emotional distress as a result of people knowing their HIV/AIDS status. Women who test positive for HIV/AIDS while their husbands are negative are viewed with intense negativity, putting them at significant risk of being rejected by their own family or community. The findings from this study revealed a significant number of women who have been living in HIV discordant relationships but have had to leave their homes and communities as a result of increasing psychological and physical abuse they receive, not only from their husbands but also from their extended family and the entire community. Discussion with a female survivor revealed that;

...without any delay, he started demanding for sex forcefully while pulling my cloths until he made it. After raping and defiling me l decided to have him as my husband $l$ lived with him for two years and gave birth to two children but later on he started mistreating me on realizing that he had already infected me with HIV/ AIDS and never wanted to live with me anymore. We used to over quarrel and fight in the house (Female survivor, Gulu).

Alcohol and Substance Abuse: As already revealed in the previous sections, alcoholism and drug use contributed to different forms of SGBV. Discussions with local leaders revealed that there was an increased use and abuse of alcohol and drugs. It was revealed that many men spend a considerable amount of time drinking as opposed to engaging in economically productive activities which would enable their families to access basic needs. As a result, when men return from their drinking places late in the evening, arguments with their wives start resulting into violence.

My husband is a drunkard, he used to come back home drunk and asks for money from me and if not money he asks for food stock that I kept in the house for future consumption. Whenever I refuse, he begins fighting me, quarrelling and use of abusive languages (vulgar") (40 year old female survivor, Nwoya) 
There are some people who abuse drugs and alcohol especially late in the night they tend to waylay females and rape them (Survivor, Amuru).

The major causes of these, especially in his department where he works is drug abuse. There are some people who are drug abusers and alcoholic and especially late in the night they tend to way-lay female raping the female but not the male. (Local leader, Kitgum)

\section{DISCUSSION OF KEY FINDINGS}

There were several forms of SGBV indentified by the study. These included; physical violence, sexual violence, socio-economic violence and emotional violence (also see Keesbury \& Askew, 2010 and IGWG of USAID, 2006). Physical violence was perceived to be the commonest form of violence mostly perpetuated by male partners against women (also see UDHS, 2006). It is also noted that this form of violence is mostly prevalent during harvesting seasons were men tend to control the proceeds from the harvest to the disadvantage of their partners and the family. Although not commonly stated especially in the public realm, physical violence against men was perceived by some study participants as a common phenomenon. It was perceived as stigimatising for men to report cases of violence committed by their partners. This is because in patriarchal society like northern Uganda, men are socialised to be strong and not amenable to abuse by women.

Sexual violence against women and girls was perceived to be high. The most common forms of sexual violence include; rape, defilement, sexual harassment, incest, early marriages and widow inheritance (Inter-Agency Standing Committee, 2005; UDHS, 2011; JRP, 2012). Other studies have shown similar findings that in post conflict areas, sexual violence manifests in different ways including survival sex, commercial sex work and early marriages (Sigsworth, 2008).

In post conflict settings like northern Uganda, early marriage has been looked at as a survival strategy against poverty. Some girls hope to enjoy greater economic security when married while the parents see bride price as an important financial asset (Gottschalk, 2007). However, young girls in marriages usually lack status and power within their marriages and their households. This exposes them to domestic violence, intimate partner violence, and isolation from their families and communities (Mensch, Bruce \& Greene, 1998; Bruce, 2005)

The most common form of socio-economic violence was denial of women the right to property ownership and inheritance as well as their right to work. In northern Uganda, property ownership is virtually patri-lineal. Therefore upon the death of a husband, his family disinherits the widow in the guise of ensuring that the property devolves to a male adult who is a relative of the deceased. Often women are evicted from their land, homes and stripped off of their possessions (Human Rights Watch, 2003; Valji, 2007). This study noted that some men deny their wives to work or get involved in income generating activities which has resulted into divorce and physical violence. This is similar to the findings from Rahman's study (1999) which found that $70 \%$ of women members of Grameen Bank reported higher levels of domestic violence after participating in economic programmes. Similarly, a study India noted that unemployed women who got unemployed had an $80 \%$ risk of violence (Krishnan, et al., 2009). This study notes that some men could not allow their wives to work because they had a perception that women spend all the money earned on themselves or their parents, nobody will be at home to care for the children and women working in offices put their money before their 
husbands and the respect becomes less. This shows that women's participation in the public sphere is perceived to challenge the normative status quo of women's subordinate position under patriarchy and may result into women neglecting their gender roles (Bukuluki \& Mugisha, 2009). The study established that emotional violence is more common than any other forms of violence in families. This form of violence is often referred to as a covert form of domestic violence where victims receive verbal abuse. It is a form of abuse characterized by a person subjecting or exposing another to behaviour that may result into psychological trauma, including anxiety and chronic depression (UNHCR, 2003; UDHS, 2006; Garcia-Moreno et al., 2006).

There are a number of structural, social and psychological drivers of SGBV revealed in this study and these include among others, poverty, power imbalances in access and control over resources, insecurity, HIV and AIDS, alcohol and drug abuse. Domestic violence resulting from control of resources in the home depicts a situation where women's rights have been infringed upon with men taking over control of the allocation and utilisation of household incomes. Similar evidence from other studies revealed that in northern Uganda, access to land and others assets is not guaranteed to women given the existence of national laws which protect women's economic rights. It has also been noted that even some women who independently own assets lack the confidence to make independent decisions with regard to the sale of such assets (Bukuluki \& Mugisha, 2009).

Limited access to productive resources hinders women to release their economic rights such as access to credit to engage in productive activities (Bukuluki \& Mugisha, 2010). On the other hand, economic empowerment women (without engaging with men) may cause friction and conflict between partners. Disagreements over the control of newly acquired assets and earnings, combined with women's changing attitudes towards traditional gender roles, improved social support and greater confidence to defend themselves against male counterparts may led to marital conflicts and intimate partner violence. Thus it is worth noting that women's participation in economic empowerment activities changes household dynamics and often results in increased risk of SGBV (Barker \&Schulte, 2010).

In northern Uganda, socially a man is the father (head) of the family and this makes him the family head. The woman on the other hand is defined as a helper to the man and to the family thus she is supposed to implement the decisions of a man (Bukuluki \& Mugisha, 2010). This traditional family setting which allowed for controls within the rural setting was disintegrated as a result of the war and men were deprived of their livelihoods and could not go to work because of insecurity. During the war, most provisions were provided by relief agencies, the organization took over the traditional and primary role of men as that of provider, and this took away some powers men wield that are linked to this role. Such deconstruction of gender roles increases risks to SGBV since in such settings men are increasingly idle and frustrated of being unable to live up to the masculine ideals of being the provider would predispose them to violence against their partners/wives (Okot, Amony and Otim, 2005). A study by Correia and Bannon (2006) noted that men failure to meet the societal expectations of what it means to be a 'real man' - being the breadwinner and household decision-maker results into violence against women and children because it is one of the few remaining ways that they can display power over others and feel like a man. Similarly, the culturally constructed masculinity and femininity qualities re-enforces the belief that women are subordinate to men. Ascribed roles and entitlements for men and women limit the females from enjoying certain rights such as engagement in income generating activities, access to and control of resources (Bukuluki \& Mugisha, 2009). 
Conflict, insecurity and lawlessness exacerbated SGBV in Northern Uganda. Studies have shown that perpetrators took advantage of the conflict to commit acts of SGBV knowing that the risk of identification is low (Skjelsbæk, 2006; ACCORD, 2010). Sexual violence during the LRA conflicts was used as a weapon of war by rebel groups and even some government forces with the aim of attacking and humiliating the enemy (Amnesty International, 2007; JRP, 2012). During the conflict, many atrocities such as domestic violence in camps was wide spread and gang raping was common (JRP, 2012).

HIV and AIDS is also a compounding driver of SGBV. Women who test positive for HIV/AIDS while their husbands are negative are viewed with intense negativity, putting them at significant risk of being rejected by their own family or community (Bukuluki \& Mugisha, 2009). Women who have been living in HIV discordant relationships had to leave their homes and communities as a result of increasing psychological and physical abuse they receive, not only from their husbands but also from their extended family and the entire community. For example women blamed for infecting male partners with HIV (also see Okot, Amony \& Otim, 2005). Alcoholism and drug use is also a key driver to SGBV. Many men spend a considerable amount of time drinking as opposed to engaging in economically productive activities which would enable their families to access basic needs

\section{CONCLUSION}

Overall, SGBV is still prevalent in post conflict Northern Uganda. Although all forms of violence are perceived to be prevalent, physical and emotional violence are perceived to be the most occurring. Men are perceived to be the main perpetrators of violence. However, there were several cases of men that reported to experience violence from women. Few men report violence to authorities because it was perceived to be stigmatizing because such men would be perceived as weak in a patriarchal society that perceives ideal men as strong and not susceptible to physical, emotional and sexual abuse by women. Early marriages come out as a major form of gender based violence which is in some communities perceived as normal and in others tolerated. Sexual violence cases in form of rape, defilement as well as incest were perceived to be on the rise in the sub-region. Several drivers to SGBV were identified including poverty, power imbalances in access and control over resources especially money, land, proceeds from farming, insecurity, blaming female partners for infecting male partners with HIV, HIV related stigma and discrimination, alcohol and substance Abuse.

\section{References}

[1] ACORD. Protection and Restitution for Survivors of Sexual and Gender Based Violence in Uganda: The legal peculiarities, the possibilities and the options. ACORD: Kampala, 2010.

[2] Akumu. C, Amony. I \& Otim. G. Suffering in Silence: A Study of Sexual and Gender Based Violence (SGBV) In Pabbo Camp, Gulu District, Northern Uganda. Gulu District Sub Working Group on SGBV, 2005.

[3] Auditor General. Special investigation report on the allegations of financial impropriety in the office of the prime minister. Office of the Auditor General: Kampala, 2012. 
[4] Barker G \& Schulte J, Engaging Men as Allies in Women's Economic Empowerment: Strategies and Recommendations for CARE Country Offices. International Center for Research on Women. CARE Norway 2010.

[5] Bukuluki. P and Mugisha. J. Baseline survey for Roco Kwo programme. Kampala: CARE International-Uganda, 2010.

[6] Bukuluki. P and Mugisha. J. knowledge, attitude and practice survey on gender equality in selected districts in northern Uganda, Acholi sub region. Kampala: Care International-Uagnda, 2009.

[7] Branch, A. International Justice, Local Injustice: The International Criminal Court in Northern Uganda, Dissent, Summer, (2004)

[8] Bruce, J. "Child Marriage in the Context of the HIV Epidemic," Population Council: Transitions to Adulthood Brief, no. 11, Sept. 2005.

[9] Brownmiller, S. Against Our Will: Men, Women and Rape. London: Penguin. [1975] 1991.

[10] Lloyd, C, ed. Growing Up Global: Changing Transitions to Adulthood in Developing Countries, Wash. DC: Nat'l Academies Press, 2005.

[11] Finnstrom, S. Living with Bad Surroundings: War and Existential Uncertainty in Acholiland, Northern Uganda. Uppsala, Sweden, 2008

[12] Dolan, C., Humanitarian Protection in Uganda: A Trojan Horse? HPG Background Paper. London: Overseas Development Institute, 2006.

[13] Galtung, J,. After Violence, Reconstruction, Reconciliation, and Resolution.” In Reconciliation, Justice and Coexistence, ed. Mohammed Abu-Nimer, 3-23. Lanham, MD: Lexington Books (2001).

[14] Garcia-Moreno C, Jansen HAFM, Ellsberg M, Heise L, Watts CH. Prevalence of intimate partner violence: findings from the WHO multi-country study on women's health and domestic violence. The Lancet. 368(9543) (2006) 1260-1269.

[15] Gottschalk, N, Uganda: early marriage as a form of sexual violence, in FMR 27, January 2007, 51-53. Also available at: http://www.fmreview.org/FMRpdfs/FMR27/34.pdf .

[16] Heise, L., Ellsberg M., and Gottemoeller, M.. Ending Violence Against Women. Population Reports. Series . No. 11. Baltimore, Maryland: Population Information Program, Johns Hopkins School of Public Health. 1999.

[17] Human Rights Watch. Double Standards: Women's Property Rights Violation in Kenya, 2003.

[18] ICG . Building a Comprehensive Peace Strategy for Northern Uganda. Africa Briefing No. 2723 June 2005, http://www.crisisgroup.org/home/index.cfm?id=3523\&l=1 (Accessed on $28^{\text {th }}$ July 2011).

[19] ICRW. Intimate Partner Violence: high cost to Households and Communities. Washington DC. International Centre for Research on Women, 2009. Available at: www.icrw.org/publications/intimate-partner-violence-high-cost-householdsandcommunities 
[20] IGWG of USAID. Addressing Gender-Based Violence through USAID's HealthPrograms: A Guide for Health Sector Program Officers. Washington, DC, 2006.

[21] Isis-WICCE. Medical Interventional Study of War Affected Kitgum District. An Isis-WICCE Report with financial support from Medica Mondiale. Isis-WICCE, Kampala, Uganda, 2006.

[22] Inter-Agency Standing Committee (IASC). Guidelines for Gender-Based Violence Interventions in Humanitarian Settings: Focusing on Prevention of and Response to Sexual Violence in Emergencies. Geneva: Inter-Agency Standing Committee, 2005.

[23] Kishor S. and Johnson K.,(2004). Profiling Domestic Violence - A Multi-Country Study, ORC Macro, 2004.

[24] Kirk , J., and Miller, M. L. Reliability and Validity in Quantitative Research. Beverly Hill, CA: Sage. 1986.

[25] Keesbury J. and Askew I. Comprehensive responses to gender based violence in low resource settings: Lessons learned from implementation. Population Council, Lusaka, Zambia, 2010 .

[26] Mensch B, Bruce J, Greene M, The Uncharted Passage: Girls' Adolescence in the Developing World, NY: Population Council, 1998.

[27] MoGLSD, National report on sexual and gender based violence. International Conference on the Great Lakes Region. Kampala: MoGLSD, 2011.

[28] OHCHR Making Peace Our Own: Victims'Perceptions of Accountability, Reconciliation and Transitional Justice in Northern Uganda. United Nations, Office of the High Commissioner for Human Rights, New York: United Nations, 2007.

[29] Rahman, A. “Women and Microcredit in Rural Bangladesh: An Anthropological Study of the Rhetoric and Realities of Grameen Bank Lending," Boulder, CO: West view Press. (1999).

[30] Sigsworth .R. Gender-Based Violence in Transition. Centre for the Study of Violence and Reconciliation; Transitional Justice Programme. Johannesburg, 2008.

[31] Skjelsbæk I. Voicing Silence: A Political Psychological Analysis of the Aftermath of the Bosnian War Rapes Thesis for the degree doctor rerum politicarum Trondheim, Norwegian University of Science and Technology Faculty of Social Sciences and Technology Management Department of Psycholog, 2006.

[32] UBOS. Uganda Demographic and Health Survey. UBOS, ICF International, Calverton, Maryland, USA, 2011.

[33] UBOS and ORC Macro. The Uganda Demographic and Health Survey. Calverton, Maryland, USA: UBOS and ORC Macro International Inc. 2007.

[34] Uganda Demographic and Health Survey 2006. Calverton, Maryland USA: Uganda Bureau of Statistics (UBOS) and Macro International Inc.

[35] UNHCR. Sexual and Gender-Based Violence against Refugees, Returnees and Internally Displaced Persons. Guidelines for Prevention and Response. UNHCR, 2003.

[36] UN Children's Fund (UNICEF). UN Joint Programme on gender-based violence programme document. Kampala: UNICEF, 2012. 
[37] UNICEF (2005) "Children bear the brunt of Uganda's 19-year old war" available at: http://www.unicef.org/infobycountry/uganda_25704.html [accessed on 17th February, 2010

[38] UNICEF. 'Suffering in Silence: A Study of Sexual and Gender Based Violence' UNICEF Uganda, 2005. http://www.unicef.org/media/media_27378.html [accessed 20 August 2009].

[39] UNICEF (2004) United Nations Children's Fund, International Rescue Committee, Christian Children's Fund, Legal Aid Project. Protected Yet Insecure 2004.

[40] Valji. N, (2007). Gender Justice and Reconciliation, International Conference: Building a Future on Peace and Justice, Nuremberg. 